\title{
Saúde pública global e o novo Regulamento Sanitário Internacional
}

Global public health and the new International Sanitary Regulation.

\section{Larissa de Paula Gonzaga e Castro}

Advogada, Mestre em Direito Internacional e Relações Internacionais. Professora da Universidade Federal do Rio de Janeiro.

Resumo: $O$ estudo destina-se a discutir o novo Regulamento Sanitário Internacional. Destaca as novidades trazidas por essa nova normativa da saúde global como também faz uma retrospectiva sanitária e normativa e a implementação do RSI no Brasil com a aplicação do método do algoritmo. O artigo conclui que a segurança sanitária internacional requer, à par da avançada regulamentação internacional sobre o controle de enfermidades e riscos à saúde, a dilatação da cooperação e interação entre países e instituições, assim como a estruturação de uma governança global em saúde justa e comprometida primordialmente com o bem estar das pessoas.

Palavras-chave: Regulamento Sanitário Internacional; regulação em saúde; riscos à saúde internacional.

Abstract: The study aims to discuss the new International Health Regulations. Highlights the innovations brought by the new rules of global health as well as looks back and sanitary regulations and the implementation of CSR in Brazil with the application of the method of the algorithm. The article concludes that international health security requires the expansion of cooperation and interaction between countries and institutions, as well as the structure of global governance in health fair and committed primarily with the welfare of the people.

Key-words: International Sanitary Regulation; health regulation; international health risk.

\section{Introdução}

Ao adentrar no campo de estudo da Saúde Global percebe-se a grande dificuldade na harmonização de normas e procedimentos, que muitas vezes encontra grandes obstáculos devido à diversidade de interesses, disparidade de modelos e serviços de saúde, escassez de recursos, falta de pessoal, etc. 
Todavia, no atual cenário mundial existem muitos riscos para a saúde da população que não se circunscrevem às fronteiras dos Estados, devido principalmente a facilidade de movimentação de pessoas e mercadorias. Problemas de saúde pública, de meio ambiente, de caráter social, dentre outros, são dotados atualmente de uma capacidade imensa de transpor as fronteiras nacionais, corroborando a premissa de que tais problemas só serão enfrentados ou solucionados de forma eficaz se houver uma atuação conjunta e multilateral dos atores envolvidos.

Estamos no campo do novo Regulamento Sanitário Internacional, que representa a evolução de um dos mais tradicionais tratados internacionais de saúde pública, que sofreu modificações substanciais, tendo seus limites expandidos. O sucesso do novo Regulamento Sanitário Internacional é devido a sua enorme relevância no campo social, pois este se revela como a via de proteção das pessoas frente a um surto epidêmico de importância internacional.

O principal instrumento que os países hoje dispõem como meio de fazer frente a esta realidade e controlar a propagação de doenças é o novo Regulamento Sanitário Internacional, aprovado na 58 Assembléia Mundial de Saúde, após alguns anos de revisão e que se encontra em vigor desde junho de 2007.

As relações entre as epidemias e deslocamento de pessoas é muito antiga, sendo relatada por Tucídides em 431 a.C., sobre a peste vinda da Etiópia que se propagou na Grécia. A pandemia da "peste negra", advinda da Mongólia, alcançou inicialmente parte da Ásia, África e Europa, correndo por todo o mundo (Menucci, 2006).

No século XIV as principais cidades do mundo estavam às margens do mediterrâneo, que concentrava o centro comercial do mundo, ligando Europa, Ásia e África. Foram nestas cidades que apareceram as primeiras tentativas de proteção contra epidemias. Segundo Edina Costa (2003, p. 181):

A idéia de contágio se fortaleceu na Idade Média fornecendo as bases para o isolamento de doentes e a quarentena, dando início ao desenvolvimento da Vigilância Epidemiológica e, com isto, o ramo da Vigilância Sanitária de Portos, no futuro também de aeroportos e fronteiras. Em Veneza, o mais importante porto da Europa para a entrada das mercadorias vindas do Oriente, ocorreram as primeiras medidas para evitar a introdução da peste. 
A partir de 1348, teve início o desenvolvimento do sistema de quarentena em Veneza e outras cidades, instituindo-se rigorosa inspeção das embarcações e de suas cargas em épocas epidêmicas. No final da Idade Média, todos os países da Europa dispunham de um Regulamento da Quarentena, uma espécie de determinação de urgência para os momentos de epidemia, o que implicava em rigoroso sistema de vigilância que dividia e esquadrinhava o espaço urbano, com registro centralizado do controle minucioso dos vivos e dos mortos.

A partir do século XIX, com o desenvolvimento industrial impulsionado pela máquina a vapor e com a abertura do Canal de Suez, o deslocamento de pessoas e mercadorias veio acentuar a propagação de enfermidades. As grandes epidemias advindas do Oriente, especialmente o cólera, avançavam rapidamente pela Europa.

Após a primeira Conferência Sanitária Internacional, direcionada a todas as nações com interesses comerciais no Mediterrâneo, foi adotada a Convenção Internacional Sanitária, em 1892, que visava unicamente combater o cólera, seguida por outra, que tratava de medidas preventivas contra a peste.

Em 1945, a Conferência das Nações Unidas estabeleceu uma nova e autônoma organização internacional de saúde. Finalmente, em 1946, foi aprovada, em Nova Iorque, a Constituição da Organização Mundial da Saúde (OMS), que entrou em vigor em 7 de abril de 1948. Em 1951 foi adotado o texto do Regulamento Sanitário Internacional (Brown; Cueto; Fee, 2006).

O processo de globalização tem influência direta sobre a saúde, pois possibilita transnacionalização das doenças transmissíveis, novas ou reemergentes. O desenvolvimento e diminuição de custos dos transportes aumentaram as viagens e o comércio internacional, facilitando que microorganismos sejam rapidamente transportados, por intermédio de pessoas, animais, insetos e alimentos, de um país a outro e de um ponto a outro do globo. ${ }^{1}$

\footnotetext{
${ }^{1}$ Interessante a compilação de Paulo Buss (2007), que afirma que "Para a maioria dos autores, a globalização é um processo econômico, social e cultural que se estabeleceu nas duas ou três últimas décadas do século XX, cujas principais características incluem, em escala nunca antes alcançada: crescimento do comércio internacional de bens, produtos e serviços; transnacionalização de megaempresas; livre circulação de capitais; privatização da economia e minimização do papel dos governos e dos Estados-nações; queda de barreiras comerciais protecionistas e regulação do comércio internacional segundo as regras da Organização Mundial do Comércio (OMC); facilidade de trânsito de pessoas e bens entre os diversos países do mundo; e expansão das possibilidades de
} 
Exemplos recentes são as difusões da SARS, do vírus do dengue e da gripe aviária. A transmissão interpessoal das febres hemorrágicas virais, como os casos recentes das febres Marburg e Ebola, na África, apresentam grande potencial epidêmico, facilitado pelos rápidos deslocamentos em viagens aéreas internacionais, o que aponta para a necessidade e a importância do reforço das redes globais de diagnóstico e vigilância em saúde, operadas pela OMS e parceiros ao redor do mundo.

O primeiro código sanitário de nível internacional de que se tem notícia é o Código Sanitário Pan-Americano², de 14 de novembro de 1924, adotado na VII Conferência Sanitária Pan-Americana, no Salón de Actos de la Antigua Academia de Ciencias Médicas, Físicas y Naturales, em Havana, Cuba, com ratificação por 18 países americanos.

A 4⿳亠丷a Assembléia Mundial da Saúde ocorreu em 1951, três anos após a entrada em vigor da constituição da OMS (WHO, 2006), e estabeleceu o primeiro Regulamento Sanitário Internacional, adotado como acordo juridicamente vinculante e apontado como primeiro código internacional de medidas para prevenir a propagação de determinadas enfermidade infecciosas (especificamente peste, febre amarela, varíola, cólera, febre recorrente e tifo), estabelecia medidas sanitárias nos pontos de entrada e saída de pessoas e mercadorias nos países, alem de indicar os requisitos para notificação e apresentação de informes. Esse Regulamento passou por modificações em 1969, 19731981.

O novo Regulamento Sanitário Internacional foi adotado na 58 Assembleia Mundial da Saúde, em 2005, (WHO, 2005 a) e entrou em vigor em 15

\footnotetext{
comunicação, pelo surgimento da chamada sociedade da informação e da grande facilidade de contato entre as pessoas devido ao aparecimento de diversos instrumentos e ferramentas, entre as quais a internet."

2 É interessante observar o caráter atual dos objetivos do Código, dispostas no seu capitulo I: "1. Prevenir la propagación internacional de infecciones o enfermedades susceptibles de transmitirse a seres humanos. 2. Estimular o adoptar medidas cooperativas encaminadas a impedir la introducción y propagación de enfermedades en los territorios de los gobiernos signatarios o procedentes de los mismos. 3. Uniformar la recolección de datos estadísticos relativos a la morbilidad y mortalidad en los países de los gobiernos signatarios. 4. Estimular el intercambio de informes que puedan ser valiosos para mejorar la sanidad pública y combatir las enfermedades propias del hombre. 5. Uniformar las medidas empleadas en los lugares de entrada para impedir la introducción de enfermedades transmisibles propias del hombre, a fin de que pueda obtenerse mayor protección contra ellas y eliminarse toda barrera o estorbo innecesario para el comercio y la comunicación internacional." (OPS, 1951).
} 
de junho de 2007, como instrumento jurídico oficial da OMS, de caráter vinculante para os Estado Membros, apresentado como codificação normativa que visa a assegurar o máximo de segurança contra a transmissão transnacional de doenças e outros riscos à saúde, por meio da adoção e cumprimento de normas e preceitos de alcance mundial, preservando a harmonia entre o comércio internacional, a circulação de pessoas e a saúde publica.

A OMS conceitua o Regulamento Sanitário Internacional de duas formas: "The International Health Regulations (2005) or 'IHR (2005)' are an international law which helps countries working together to save lives and livelihoods caused by the international spread of diseases and other health risks." $\mathrm{e}$ "The International Health Regulations (IHR) are an international legal instrument that is binding on 194 countries across the globe, including all the Member States of WHO. Their aim is to help the international community prevent and respond to acute public health risks that have the potential to cross borders and threaten people worldwide."

O artigo 1ำ do Regulamento Sanitário Internacional de 2005 estabelece:

For the purposes of the International Health Regulations (hereinafter "the IHR" or "Regulations"):

[...] "public health emergency of international concern" means an extraordinary event which is determined, as provided in these Regulations:

(i) to constitute a public health risk to other States through the international spread of disease and

(ii) to potentially require a coordinated international response;

Assim, para que um evento seja notificável, constituindo uma Emergência de Saúde Pública de Importância Internacional, ele deve:

- ser extraordinário, logo, entendemos que doenças endêmicas não são notificáveis com uma dessas emergências, a menos que surto acontecesse em área não endêmica; ou fosse detectada mutação ou resistência microbiana; ou apresentasse alguma característica especial que qualificasse o evento como ESPII, como novos sintomas ou elevada gravidade;

\footnotetext{
${ }^{3}$ Conceito disponível em http://www.who.int/csr/ihr/howtheywork/faq/en/index.html. Acesso em 27 ago. 2012.

${ }^{4}$ Conceito disponível em http://www.who.int/features/qa/39/en/index.html. Acesso em 27 ago. 2012.
} 
- constituir em risco para a saúde pública para outros Estados, devido à propagação internacional da doença, ou seja, deve ser observada a conjuntura do evento, considerando extensão do surto, o local e o momento de ocorrência, o meio e a velocidade de propagação etc.

- potencialmente exigir uma resposta internacional coordenada.

Para uniformizar a tomada de decisão quanto ao enquadramento de um evento como ESPII foi elaborado um algoritmo e um documento de instrução com exemplos de aplicação do algoritmo, constantes no Anexo II do Regulamento Sanitário Internacional de 2005 (WHO, 2005 b).

Observe-se a útil adaptação do algoritmo para a língua portuguesa feita por Eduardo Hage Carmo (Figuras 1 e 2).

A aplicação do algoritmo supra é fundamental para harmonização de decisões sobre eventos que devem ser qualificados como ESPII e, consequentemente, notificados a OMS pelos Estados Membros.

O novo RSI inovou em diversos aspectos, as mudanças mais substanciais incluídas na nova versão do Regulamento são a vinculação da necessidade de notificação à ocorrência de uma emergência de saúde pública de importância internacional (ESPII); ampliação de âmbito de aplicação, não mais limitado a um número taxativo de doenças; revogação expressa de acordos, convenções e regulamentos sanitários internacionais; previsão explícita de colaboração externa; possibilidade de serem feitas recomendações permanentes e temporárias por parte da OMS e estabelecimento de capacidades nacionais básicas para detectar, avaliar, notificar e informar emergências de saúde pública de importância internacional. 
Figura 1 - Instrumento de decisão para avaliação e notificação de eventos que podem constituir uma ESPII

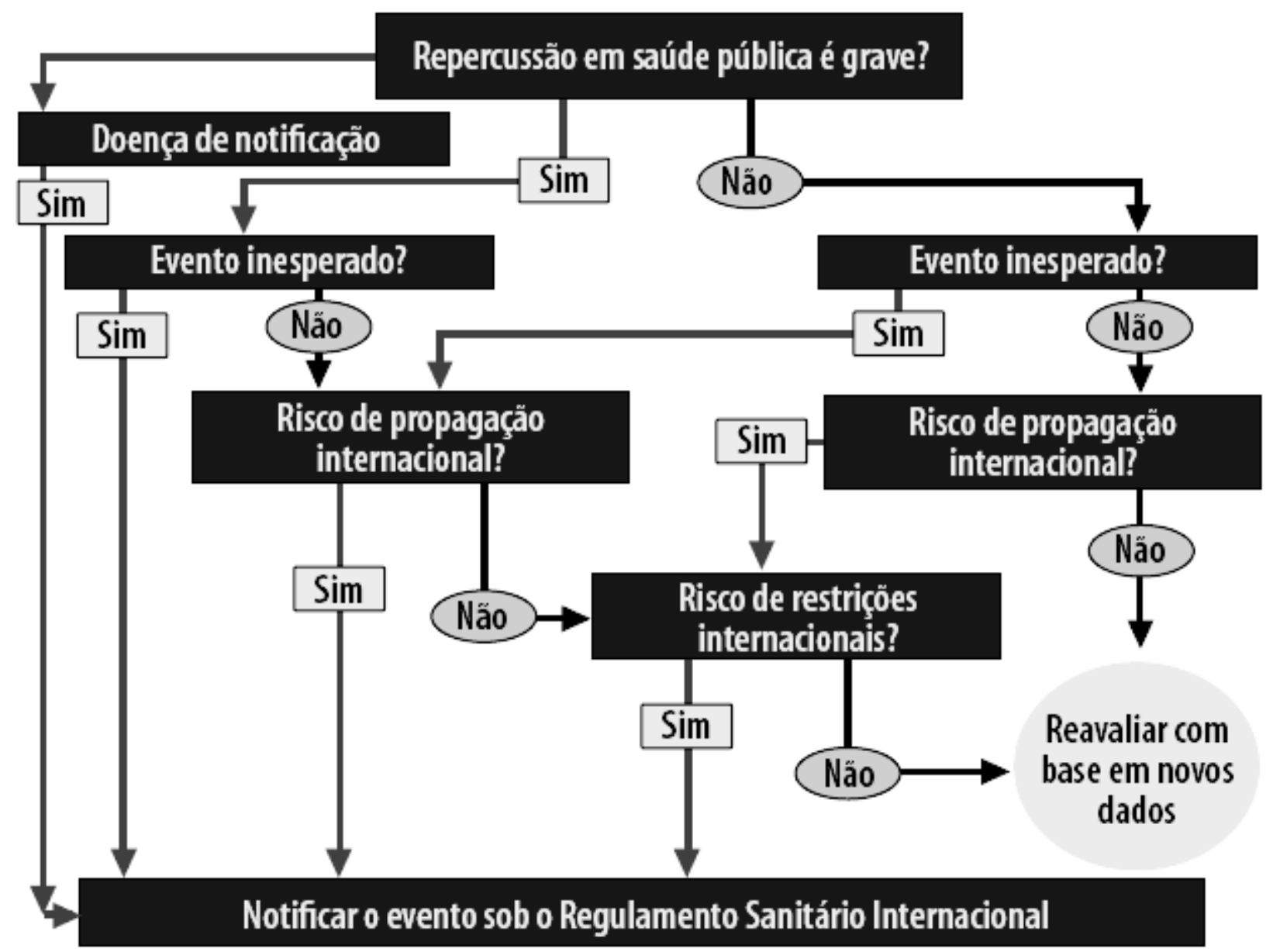

Fonte: adaptado do Anexo II do RSI (2005)

Fonte: Secretaria de Vigilância em Saúde, do Ministério da Saúde (Brasil) (SVS/MS) - Boletim Eletrônico Epidemiológico in Carmo, 2007, p 3. 
FIGURA 2 - Doenças de notificação obrigatória e eventos que devem ser avaliados com uso do instrumento de decisão

\section{Eventos detectados pelo sistema nacional de vigilância}

Doenças de notificaçăo obrigatória

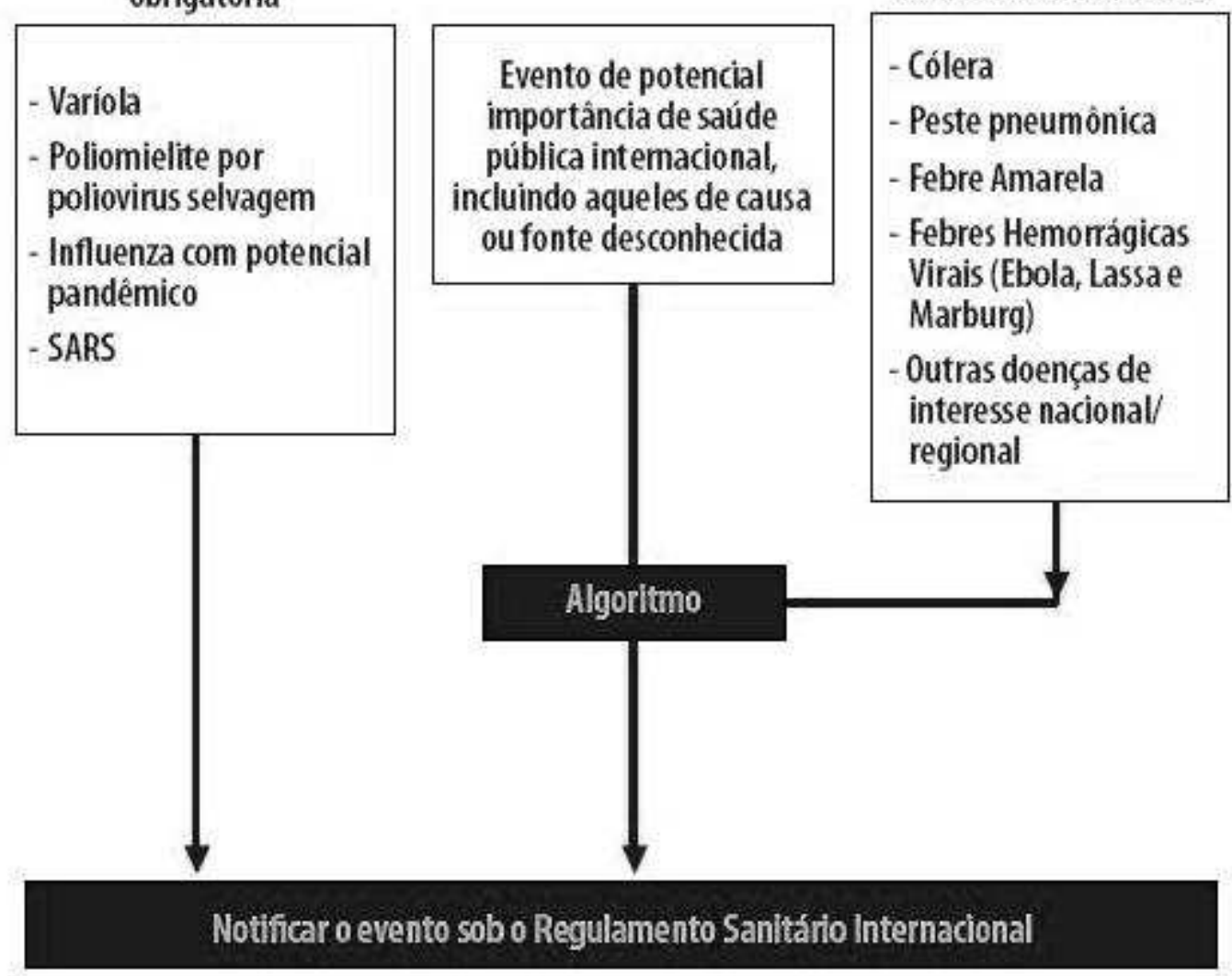

Doenças avaliadas pelo instrumento de decisão

- Cólera

- Peste pneumónica

re Amarela

- Febres Hemorrágicas Virais (Ebolat Lassae

regional

Fonte: adaptado do Anexo II do RSI (2005)

Fonte: Secretaria de Vigilância em Saúde, do Ministério da Saúde (Brasil) (SVS/MS) - Boletim Eletrônico Epidemiológico in Carmo, 2007, p 3.

A grande inovação do artigo 9 consiste em admitir que a OMS poderá levar em conta fontes não oficiais de informação para conhecimento dos eventos que poderiam constituir uma Emergência de Saúde Pública de Importância Internacional. Neste caso deverá ser consultado preliminarmente o Estado onde possivelmente esteja ocorrendo o evento, que terá 24 horas para corroborar ou desqualificar a informação recebida.

O texto do RSI de 2005 é composto de sessenta e seis artigos, agrupados em dez partes e nove anexos. A Parte I, composta dos artigos $1^{\circ}$ a $4^{\circ}$, 
estabelece definições dos termos empregados ao longo do instrumento, 0 propósito, o alcance, os princípios e as autoridades responsáveis pela implementação das medidas de saúde nas respectivas áreas de jurisdição.

A Parte II, que trata da informação e resposta em Saúde Pública, abarca os artigos $5^{0}$ ao 14 . O primeiro tema abordado refere-se à capacidade de detectar, avaliar, notificar e informar a ocorrência de eventos, segundo os parâmetros do Anexo I. A notificação deve obedecer ao instrumento de decisão que constante do Anexo II. O artigo 12 caracteriza o conceito de ESPII, analisado no item 3.2.1 supra, que, de acordo com o artigo 13, deflagrará a resposta de saúde pública e ensejará a cooperação da OMS com organizações intergovernamentais e organismos internacionais, segundo estabelece o artigo 14.

As recomendações são reguladas na Parte III, que compreende os artigos 15 a 18. As recomendações serão temporárias, quando se tratar de uma ESPII, e podem ser editadas recomendações de caráter permanente em relação a pessoas, bagagens, cargas, contêineres, meios de transporte, mercadorias e encomendas.

A Parte IV do Regulamento Sanitário Internacional, que compreende os artigos 19 a 22, dispõe sobre os pontos de entrada dos países, que compreendem os portos e aeroportos dotados das capacidades indicadas no Anexo I.

A Parte V, artigos 23 a 34, trata das Medidas de Saúde Pública contendo normas de saúde na chegada e na partida, regras relativas aos operadores de meios de transporte, embarcações, aeronaves, caminhões, trens e ônibus civis em trânsito, disposições especiais para viajantes, mercadorias, contêineres e terminais de contêineres.

A Parte VI, artigos 35 a 39, versa sobre os documentos de saúde, estabelecendo que além dos documentos indicados no RSI e nas recomendações da OMS, nenhum documento de saúde será exigido no tráfego internacional, salvo os previstos em acordos internacionais pertinentes a condições sanitárias de mercadorias ou cargas comerciais internacionais, 
buscando evitar a imposição de barreiras sanitárias desnecessárias aos países. $^{5}$

A Parte VII, composta somente dos artigos 40 e 41, e estabelece que o Estado Membro não deve cobrar qualquer encargo dos viajantes sobre as medidas de proteção à saúde, com exceção daqueles que buscam residência temporária ou permanente.

A Parte VIII, artigos 42 a 45, estabelece Disposições Gerais, tais como as regras sobre implementação das medidas de saúde, medidas adicionais, colaboração e assistência, manuseio de substâncias biológicas, reagentes e materiais para fins de diagnóstico.

A Parte IX, artigos 47 a 53, versa sobre o cadastro de peritos do Regulamento Sanitário Internacional, o Comitê de Emergências e o Comitê de Revisão.

A Parte X, artigos 54 a 66 , estabelece os procedimentos de emendas ao Regulamento Sanitário Internacional, o mecanismo de solução de controvérsias, assim como os procedimentos de entrada em vigor e de reservas. O Regulamento contém, ainda, nove Anexos, que tratam de diversos temas.

\section{Conclusão}

Os novos cenários epidemiológicos, os câmbios nos padrões habituais de transmissão de enfermidades, os riscos decorrentes das agressões ao meio ambiente, as mudanças climáticas e catástrofes naturais, o crescimento da população e uma grande diversidade de agentes patogênicos, não apenas biológicos, mas também químicos e radioativos, evidenciam a necessidade de readequação e aprimoramento permanente das estruturas, processos, práticas, instrumentos e estratégias tradicionais de administração sanitária dos riscos.

Os riscos, mais do que nunca, não respeitam as fronteiras, adquirindo proporções transnacionais, e a harmonização das normas de segurança sanitária no nível internacional é indispensável para garantir a saúde global, principalmente se considerarmos o nível elevado de comércio interpaíses e a

\footnotetext{
${ }^{5}$ Os documentos de saúde relacionados nos arts. 36 a 39 do Regulamento Sanitário Internacional são: a) certificados de vacinação e outras medidas profiláticas, aplicáveis aos viajantes; b) declaração marítima de saúde, a ser preenchida pelo capitão do navio e referendada pelo médico de bordo, se houver; c) parte de saúde da declaração geral da aeronave, a ser preenchida pelo respectivo comandante; e d) certificados de controle sanitário da embarcação.
} 
facilidade da mobilidade de pessoas. Está estabelecido o norte aos legisladores dos Estados Membros para criar as normas jurídicas que se relacionem com a segurança sanitária e, aos executores, para observarem o escopo do instrumento ao executar tais normas.

Alcançar padrões mínimos de segurança sanitária internacional depende, sobretudo, de real vontade política, comprometida com a reestruturação do aparato sanitário em âmbito internacional, nacional e regional. A existência de infra-estrutura básica adequada, investimento em longo prazo e uma efetiva governança em saúde são requisitos indispensáveis à identificação, notificação e resposta a eventos sanitários que podem apresentar riscos internacionais de modo eficiente.

A tão almejada segurança sanitária internacional requer a dilatação da cooperação e interação entre países e instituições, assim como a estruturação de uma governança global em saúde justa e comprometida primordialmente com o bem estar das pessoas. 


\section{Referências}

BROWN, TM.; CUETO, M; FEE, E. The World Health Organization and the Transition from 'International' to 'Global' Public Health. American Journal of Public Health, 96(1):62-72, jan. 2006. ISSN 1541-0048.

BUSS, PM. Globalização, pobreza e saúde. Ciência e Saúde Coletiva, 12(6), nov./dez. 2007. ISSN 1413-8123

CARMO, EH. Regulamento sanitário internacional, emergências de saúde pública, liberdades individuais e soberania. Revista de Direito Sanitário. 8(1):6164, mar./jun. 2007. ISSN 1516-4179.

COSTA, EA. Vigilância Sanitária e Proteção da Saúde. In: ARANHA, MI (Org.) Direito sanitário e saúde pública. Brasília : Ministério da Saúde, 2003.

MENUCCI, DL. O Regulamento Sanitário Internacional (2005) e a Vigilância em Saúde. Revista de Direito Sanitário. 7(2):118-150, 2006. ISSN 1516-4179.

OFICINA SANITARIA PANAMERICANA. Tema 15: revisión del Código Sanitario Panamericano en relación con el Reglamento Sanitario Internacional. Washington : Organización Sanitaria Panamericana, 1951. [on line] Disponível em: http://hist.library.paho.org/spanish/GOV/CE/CE14 7.pdf . Acesso em: $17 \mathrm{dez}$. 2010.

WORLD HEALTH ORGANIZATION. Constitución de La Organización Mundial de La Salud. Documentos básicos, suplemento de la 45a edición, octobre de 2006. [on line] Disponível em: http://www.who.int/governance/eb/ who_constitution_sp.pdf. Acesso em 14 dez. 2008.

WORLD HEALTH ORGANIZATION. Revision of the International Health Regulations. (WHA 58.3), 2005. (a) [on line] Disponível em: http://www.who.int/gb/ebwha/pdf files/WHA58/WHA58 3-en.pdf. Acesso em: 08 ago. 2012.

WORLD HEALTH ORGANIZATION. International Health Regulations (2005). (b) [on line] Disponível em: http://www.who.int/ihr/9789241596664/en/index.html . Acesso em: 26 set. 2012.

WORLD HEALTH ORGANIZATION. Proceso de revisión del Reglamento Sanitario Internacional (Regulamento Sanitário Internacional). [on line] Disponível em: http://www.who.int/csr/ihr/revision/es/index.htmlAcesso em: 10 ago. 2012. 